\title{
A persistência da desigualdade, o endividamento crescente e o caminho da eqüidade
}

\author{
EDUARDO MATARAZZO SUPLICY
}

$\mathrm{U}$ MA DAS características marcantes da economia brasileira nas últimas décadas, incluindo os seis anos em que foi implementado o Plano Real, é o elevadíssimo grau de concentração de renda e de riqueza. Estudo recente do IPEA (1) ressalta que o grau de desigualdade na sociedade brasileira é um dos mais altos do mundo. O Brasil é o país que apresenta maior diferença entre a renda média dos $10 \%$ mais ricos e a dos $40 \%$ mais pobres. Em nosso caso, essa diferença é de nada menos que 28 vezes! O Brasil também é o único país em que a razão da renda média dos $20 \%$ mais ricos da população e a dos $20 \%$ mais pobres supera o dilatado valor de 30, chegando a 31. No Relatório sobre o Desenvolvimento do Mundo 1999-2000, do Banco Mundial, o Brasil é o vice-campeão mundial da desigualdade, com um índice Gini de 0,60 (1995), só perdendo para Serra Leoa, 0,629 (1989).

"No que se refere ao Plano Real", observam os autores do estudo do IPEA, "não dispomos de evidência alguma de que tenha produzido qualquer impacto significativo sobre a redução da desigualdade, apesar da pobreza ter sofrido redução importante." Houve declínio pouco relevante no grau de desigualdade de 1989 a 1992. Nos anos posteriores ao Plano Real o grau de desigualdade permaneceu estável e similar ao de 1993, mas sempre superior ao de 1992, conforme indicado na tabela 1.

No período de 1977 a 1998, salvo no ano de 1981, os que representavam $1 \%$ dos mais ricos da população brasileira tiveram uma participação na renda agregada maior do que a dos $50 \%$ mais pobres, sem modificação significativa nos anos recentes do Plano Real, como demonstrado na tabela 2 .

Como se explica a persistência do fenômeno da intensa desigualdade, em que pese ter havido desde 1994, com a diminuição significativa da inflação, a quase eliminação de um dos fatores que contribuíam fortemente para que os mais pobres não conseguissem superar as suas dificuldades? 
Tabela 1

Indicadores de desigualdade de renda

\begin{tabular}{c|c|c}
\hline Ano & $\begin{array}{c}\text { Coeficiente } \\
\text { de Gini }\end{array}$ & $\begin{array}{c}\text { Razão entre a } \\
\text { renda média dos } \\
10 \% \text { mais ricos e } \\
40 \% \text { mais pobres }\end{array}$ \\
\hline 1977 & 0,62 & 26,8 \\
1978 & 0,60 & 25,0 \\
1979 & 0,59 & 22,6 \\
1981 & 0,59 & 22,0 \\
1982 & 0,60 & 23,2 \\
1983 & 0,60 & 23,7 \\
1984 & 0,59 & 22,6 \\
1985 & 0,60 & 23,8 \\
1986 & 0,59 & 22,3 \\
1987 & 0,60 & 24,7 \\
1988 & 0,62 & 27,3 \\
1989 & 0,64 & 30,7 \\
1990 & 0,62 & 27,1 \\
1992 & 0,58 & 21,8 \\
1993 & 0,60 & 24,5 \\
1995 & 0,60 & 24,1 \\
1996 & 0,60 & 24,6 \\
1997 & 0,60 & 24,5 \\
1998 & 0,60 & 24,1 \\
\hline
\end{tabular}

Fonte: IBGE/Pesquisa Nacional por Amostra de Domicílios, PNAD apud Barros, et al., 2000. Nota: O Índice de Gini mede o grau de desigualdade na distribuição de renda.
Tabela 2

Participação dos 50\% mais pobres e dos $1 \%$ mais ricos na renda agregada

\begin{tabular}{l|c|c}
\hline Ano & $\begin{array}{c}50 \% \text { mais } \\
\text { pobres }\end{array}$ & $\begin{array}{c}1 \% \text { mais } \\
\text { rico }\end{array}$ \\
\hline 1977 & 11,7 & 18,5 \\
1978 & 12,0 & 13,6 \\
1979 & 12,7 & 13,6 \\
1981 & 13,0 & 12,8 \\
1982 & 12,5 & 13,2 \\
1983 & 12,3 & 13,6 \\
1984 & 12,8 & 13,3 \\
1985 & 12,4 & 14,3 \\
1986 & 12,9 & 13,9 \\
1987 & 12,0 & 14,3 \\
1988 & 11,3 & 14,4 \\
1989 & 10,5 & 16,7 \\
1990 & 11,3 & 14,3 \\
1992 & 13,1 & 13,3 \\
1993 & 12,3 & 15,1 \\
1995 & 12,3 & 13,9 \\
1996 & 12,1 & 13,6 \\
1997 & 12,1 & 13,8 \\
1998 & 12,3 & 13,9 \\
\hline & & \\
\hline
\end{tabular}

Fonte: IBGE/PNAD

Nota: A distribuição utilizada foi a de domicílios segundo a renda domiciliar per capita.

Inúmeras vezes as principais autoridades econômicas do governo federal, como Pedro Malan, Gustavo Franco e Armínio Fraga, sustentaram que o Plano Real estava tendo forte impacto distributivo ao reduzir drasticamente o imposto inflacionário que tanto atingia os mais pobres. Estes últimos não dispunham de recursos e conhecimento suficientes para se protegerem dos efeitos da inflação, ao passo que os mais ricos não só tinham acesso aos mecanismos de indexação, como conseguiam, por vezes, tirar proveito do fenômeno da alta intensa e generalizada de preços. 
Pois bem. Se a inflação foi reduzida tão abruptamente, passando de mais de $2000 \%$ ao ano em 1994, para patamares sempre inferiores a $10 \%$ ao ano a partir de 1996, conforme demonstrado na tabela 3, por que não houve melhoria no que diz respeito à maior eqüidade na distribuição? Essa é uma questão que merece ser estudada pelos pesquisadores brasileiros. Pretendo neste ensaio levantar algumas hipóteses explicativas e sugerir algumas políticas públicas que possam contribuir para reverter este quadro.

Tabela 3

Evolução dos Índices de Preços

(INPC/IBGE) - 1990-2000

\begin{tabular}{r|r}
\hline Ano & INPC/IBGE $(\%)$ \\
\hline 1990 & $2.863,90$ \\
1991 & 423,85 \\
1992 & 992,91 \\
1993 & $1.936,32$ \\
1994 & $2.111,63$ \\
1995 & 21,21 \\
1996 & 9,53 \\
1997 & 4,34 \\
1998 & 2,95 \\
1999 & 8,43 \\
$2000^{*}$ & 1,10 \\
\hline
\end{tabular}

Obs.: até junho de 2000

\section{Razões para a persistência da desigualdade}

A persistência da desigualdade se deve à orientação da política governamental, caracterizada por taxas de juros altíssimas, sobrevalorização cambial (até janeiro de 1999), abertura (comercial e financeira) e privatização mal planejadas. Contribuíram também para essa persistência a forma como foram destinados os empréstimos das instituições oficiais de crédito, muito mais para as grandes do que para as micro, pequenas e médias empresas, a maneira como foi conduzido o Programa de Estímulo à Reestruturação e ao Fortalecimento do Sistema Financeiro Nacional (PROER), o êxodo de agricultores decorrente da política agrícola, a insuficiência do ritmo da reforma agrária e a inadequação ou debilidade das políticas sociais. Voltarei a essas questões mais adiante. 
No plano financeiro, tivemos o crescimento do endividamento interno do setor público e do endividamento externo do país. A dívida interna líquida do setor público, incluindo os três níveis de governo e as empresas estatais, cresceu de R\$170,3 bilhões, em 1995, para R\$ 407,8 bilhões em 1999, passando de $24,5 \%$ para $37 \%$ do PIB. A dívida externa total do país passou de R\$ 154,8 bilhões, em 1995, para R\$ 423,8 bilhões, em 1999, ou seja, cresceu de $22,2 \%$ para $38,5 \%$ do PIB, segundo dados do Banco Central.

Essa combinação de taxas de juros e carga crescente de endividamento certamente contribui para explicar a persistência da desigualdade. Não é difícil perceber o porquê.

Afinal, quais são as pessoas que mais recebem rendimentos na forma de juros? Quem são os proprietários de títulos da dívida pública e depósitos bancários? São primordialmente os que já têm níveis mais altos de renda e riqueza. Os mais pobres poupam pouco e são com freqüência devedores líquidos, obrigados a pagar as taxas especialmente altas que o sistema financeiro brasileiro cobra das pessoas físicas.

Taxas de juros altas atraem capitais externos para o Brasil, mas têm o efeito de diminuir os investimentos produtivos, a atividade econômica e, conseqüentemente, o nível de emprego. O desemprego

o desemprego aumentou de forma substancial durante o Plano Real ... atinge de maneira particularmente severa os mais pobres. Além disso, com menores oportunidades de emprego, os trabalhadores sofrem diminuição de seu poder de barganha e da possibilidade de conseguir ganhos em suas remunerações, até mesmo para acompanhar os aumentos de produtividade. Assim, normalmente, o aumento do desemprego conduz à maior concentração de renda. $\mathrm{O}$ desemprego aumentou de forma substancial durante o Plano Real, conforme dados das tabelas 4 e 5 .

As altas taxas de juros também dificultam as condições de acesso ao crédito para as empresas pequenas e médias em relação às maiores, sobretudo as multinacionais que têm acesso às fontes internacionais de financiamento, não tão facilmente acessíveis às empresas menores.

Para os consumidores de baixa renda a possibilidade de compra de bens e serviços, inclusive casa própria e bens duráveis, torna-se mais difícil com a elevação das taxas de juros. 
Tabela 4

IBGE - Taxas de desemprego aberto

Médias anuais. Regiões metropolitanas

\begin{tabular}{l|r|r|r|r|r|r|r|r|r|r}
\hline & 1991 & 1992 & 1993 & 1994 & 1995 & 1996 & 1997 & 1998 & 1989 & $2000^{*}$ \\
\hline Brasil & 4,83 & 5,80 & 5,31 & 4,96 & 4,63 & 5,46 & 5,66 & 7,6 & 7,56 & 8,94 \\
Belo Horizonte & 4,51 & 5,29 & 4,85 & 4,71 & 4,15 & 5,07 & 5,80 & 8,21 & 8,63 & 9,67 \\
Porto Alegre & 4,62 & 5,96 & 4,23 & 4,32 & 4,72 & 6,25 & 5,89 & 7,95 & 7,80 & 8,23 \\
Recife & 6,76 & 9,59 & 9,87 & 7,33 & 5,86 & 6,18 & 6,46 & 9,72 & 8,92 & 8,99 \\
Rio de Janeiro & 3,92 & 4,48 & 4,51 & 4,44 & 3,70 & 3,94 & 4,01 & 5,92 & 5,85 & 6,33 \\
Salvador & 6,16 & 7,05 & 6,98 & 7,33 & 6,93 & 7,14 & 8,19 & 9,77 & 10,60 & 11,43 \\
São Paulo & 5,98 & 7,11 & 6,13 & 5,84 & 5,53 & 6,71 & 7,15 & 9,40 & 9,11 & 9,00 \\
\hline
\end{tabular}

Obs.: valores até junho.

Fonte: IBGE - Pesquisa Mensal de Emprego.

Tabela 5

Fundação Seade/Dieese - Taxa de desemprego total

Médias anuais: 1990 - 2000

\begin{tabular}{c|c|c|c}
\hline Anos & $\begin{array}{c}\text { Região metropolitana } \\
\text { da RMSP }\end{array}$ & $\begin{array}{c}\text { Município de } \\
\text { São Paulo }\end{array}$ & $\begin{array}{c}\text { Demais municípios } \\
\text { da RMSP }\end{array}$ \\
\hline 1990 & 10,0 & 9,5 & 11,0 \\
1991 & 11,6 & 10,7 & 13,5 \\
1992 & 14,9 & 14,0 & 16,7 \\
1993 & 14,7 & 13,5 & 16,9 \\
1994 & 14,3 & 13,2 & 16,2 \\
1995 & 13,2 & 12,3 & 14,7 \\
1996 & 15,0 & 14,0 & 16,8 \\
1997 & 15,7 & 14,6 & 17,9 \\
1998 & 18,2 & 17,0 & 20,3 \\
1999 & 13,6 & 17,9 & 22,0 \\
$2000^{*}$ & 18,3 & 16,9 & 20,7 \\
\hline
\end{tabular}

Obs.: valores até junho

Fonte: Fundação Seade/Dieese 
Tabela 6

Participação de rendimentos na composição do PIB do Brasil: 1991-1998

\begin{tabular}{c|c|c}
\hline Ano & $\begin{array}{c}\text { Remuneração } \\
\text { dos empregados } \\
\text { e dos autônomos }\end{array}$ & $\begin{array}{c}\text { Excedente } \\
\text { operacional } \\
\text { bruto }\end{array}$ \\
\hline 1991 & 49 & 38 \\
1992 & 50 & 38 \\
1993 & 51 & 35 \\
1994 & 46 & 38 \\
1995 & 44 & 40 \\
1996 & 45 & 41 \\
1997 & 43 & 43 \\
1998 & 42 & 44 \\
\hline
\end{tabular}

Fonte: IBGE, Diretoria de Pesquisas, Departamento de Contas Nacionais, Sistema de Contas Nacionais do Brasil, 1998. O IBGE define o excedente operacional bruto como o saldo resultante do valor adicionado deduzido das remunerações pagas aos empregados, dos rendimentos dos autônomos e dos impostos líquidos de subsídios. É uma medida do excedente gerado pela produção antes da dedução de quaisquer encargos na forma de juros, rendas ou outros rendimentos de propriedade a pagar sobre ativos financeiros, terrenos ou outros ativos tangíveis.

À medida que os governos municipais, estaduais e da União tiveram que pagar um serviço da dívida crescente, foram se estrangulando as oportunidades de gastos para as finalidades de maior relevância nas áreas de educação, saúde, habitação, saneamento, reforma agrária, meio-ambiente, e demais medidas sociais de natureza redistributiva, e que poderiam colaborar decisivamente para a erradicação da miséria ou da pobreza absoluta no Brasil.

Assinale-se, por exemplo, que os juros da dívida interna passaram de R\$ 12,1 bilhões em 1995, para R\$37,06 bilhões em 1999, portanto, de $1,7 \%$ para $3,4 \%$ do PIB, como pode ser verificado pelos dados do Sistema de Administração Financeira da União (SIAFI).

Esse conjunto de fatores contribui provavelmente para entender algumas informações registradas nas Contas Nacionais. A participação dos empregados no Produto Interno Bruto caiu de 45\% em 1993, para 36\% em 1998, enquanto, em contrapartida, aumentou a participação do Excedente Operacional Bruto (EOB), que inclui a remuneração do capital, ou seja, os aluguéis, lucros e juros.

A remuneração dos autônomos, que era de 7\% em 1991, permaneceu estável em 6\% com relação ao PIB de 1992 até 1998. Assim, considerando a remuneração dos empregados, mais a dos autônomos, observa-se que ela atingiu o máximo de 51\%, na década, no ano de 1993, decrescendo para $42 \%$, em 1998, conforme mostrado na tabela 6 . 
Segundo estimativa feita pelo professor Márcio Pochmann (2) com base na PNAD, a participação do trabalho na renda nacional continuou a diminuir em 1999, passando para 40,9\%. Infelizmente, o IBGE não distingue qual o valor da parcela dos juros, aluguéis e lucros que compõem o EOB, o que impede uma análise mais acurada.

É muito importante também que venhamos a aprofundar os estudos acerca dos efeitos sobre a distribuição da riqueza decorrentes da maneira como o governo resolveu realizar as privatizações das empresas estatais. Isso se deu mediante financiamento da venda das empresas estatais para grugrupos econômicos privados adquiriram em condições vantajosas o controle de empresas... pos privados, a taxas de juros relativamente baixas obtidas junto ao BNDES e a outras instituições oficiais, assim como pela mobilização das entidades de previdência fechadas ligadas a empresas estatais, cujas diretorias em sua maioria respondem aos desígnios governamentais. Dessa maneira, diversos grupos econômicos privados adquiriram em condições vantajosas o controle de empresas que antes eram estatais e pertenciam, em tese, ao conjunto da população.

Da mesma forma, será importante aprofundar os estudos relativos aos efeitos sobre a concentração do patrimônio, em especial no setor financeiro, decorrente das operações do PROER ocorridas desde 1995. Por esse programa o Executivo federal criou uma linha de crédito destinada a sanear as instituições financeiras que apresentavam graves problemas de liquidez, como os bancos Nacional, Econômico, Bamerindus, Mercantil, Banorte, Crefisul, entre outros, com taxas de juros relativamente menores que as praticadas no mercado, para que parte dos seus ativos e passivos pudesse ser absorvida por instituições, em princípio mais saudáveis financeiramente, como o Unibanco, o Excel, cuja situação, entretanto, acabou se mostrando problemática, e depois o Bilbao-Viscaia, o HSBC e outros.

Muito embora as autoridades econômicas tenham justificado o custo dessas operações como bem menores do que as que outros países tiveram de realizar para evitar crises financeiras mais sérias, o efeito líquido do PROER representou mais um mecanismo de concentração na economia brasileira e contribuiu para que o Banco Central apresentasse resultados contábeis negativos, em vários anos. Por exemplo, em 1999, a autoridade monetária apresentou um prejuízo de R\$13.043,8 milhões. 
Tabela 7

Desembolso do Sistema BNDES por porte de empresa (em \%)

(Os percentuais foram calculados com base em valores de R \$ milhões de abril/2000)

\begin{tabular}{l|r|r|r|r|r|r}
\hline Porte & \multicolumn{1}{|c|}{1995} & \multicolumn{1}{|c|}{1996} & \multicolumn{1}{|c|}{1997} & 1998 & \multicolumn{1}{c|}{1999} & $2000^{\text {** }}$ \\
\hline Micro / pequena* & 11,7 & 8,5 & 5,5 & 2,8 & 4,6 & 8,1 \\
Média & 2,1 & 2,5 & 0,8 & 4,8 & 5,6 & 8,3 \\
Grande & 75,4 & 76,9 & 85,3 & 85,9 & 83,9 & 74,8 \\
Subtotal & 89,2 & 87,9 & 91,6 & 93,5 & 94,2 & 91,3 \\
Pessoa Física & 8,4 & 4,2 & 6,0 & 4,5 & 5,0 & 8,0 \\
Adm. Pub. Direta & 2,4 & 7,9 & 2,3 & 2,0 & 0,8 & 0,8 \\
Total & 100 & 100 & 100 & 100 & 100 & 100 \\
\hline
\end{tabular}

Fonte: BNDES

Obs.: * Inclui empresas catalogadas no BNDES como micro ou pequena e setor agrícola

** Valores anualizados a partir do desembolso do primeiro trimestre de 2000.

Tabela 8

Desembolso do Sistema BNDES por porte de empresa (em \%) 1995 a 2000

\begin{tabular}{l|c|r}
\hline \multirow{2}{*}{ Porte } & \multicolumn{2}{|c}{ Total de Desembolsos } \\
\cline { 2 - 3 } & Valores & $\%$ \\
\hline Micro / Pequena & $6.430,7$ & 6,1 \\
Média & $4.319,0$ & 4,1 \\
Grande & $84.986,3$ & 80,4 \\
Outros & $9.991,0$ & 9,4 \\
Total & $105.727,0$ & 100 \\
\hline
\end{tabular}

Fonte: BNDES

Obs.: valores em R $\$$ milhões de abril/2000

* Inclui empresas catalogadas no BNDES como micro ou pequena e setor agrícola

Outro fator que colaborou como força concentradora foi a tendência de as instituições financeiras oficiais, como o BNDES, o Banco do Brasil e outras, terem concentrado suas operações de crédito a taxas mais baixas do que as de mercado, sobretudo junto às maiores empresas. Pode-se notar, pela tabela 7, que para o Sistema BNDES, no período 1995 até 1998, houve uma participação crescente dos desembolsos para as grandes empresas, com uma tendência de reversão em favor das micro, pequenas e médias empresas no período 1999-2000. Todavia, ainda que a proporção de desembolsos para micro, pequenas e médias empresas tenha passado de $7,6 \%$ para $16,4 \%$ do total de 1998 para o primeiro semestre de 2000, o que constitui uma evolução saudável, esta última proporção está abaixo dos 17,8\% observados em 1995. 
Tomando-se em conta o período de 1995 até o primeiro trimestre do ano 2000 , observa-se, pelos dados da tabela 8 , que os desembolsos para as grandes empresas foram de $80,4 \%$ do total, enquanto as operações de crédito destinadas às micro, pequenas e médias empresas representaram apenas $10,2 \%$ do total dos desembolsos.

No que diz respeito à estrutura fundiária, em que pese ter o governo federal realizado o assentamento de 400 mil famílias entre 1995 a junho de 2000, segundo dados do INCRA, a política agrícola desenvolvida no mesmo período - conforme alertou o professor Guilherme Leite da Silva Dias, em pronunciamento feito ao deixar a Secretária Executiva do Ministério da Agricultura - causou a saída de um número muito maior de famílias das atividades agrícolas. Não é de estranhar que a concentração fundiária, segundo os dados do INCRA, tenha se mantido intensamente desigual, ao longo dos anos 90, conforme demonstram os dados da tabela 9. Em 1992, as 2,8\% maiores propriedades detinham $55,3 \%$ da área agricultável. Em 1998, essas propriedades representavam $2,9 \%$ dos imóveis rurais e $57,4 \%$ dessa área.

Tabela 9

Estrutura Agrária Brasileira - 1992-1998

\begin{tabular}{|c|c|c|c|c|c|c|c|c|}
\hline & \multicolumn{4}{|c|}{1992} & \multicolumn{4}{|c|}{1998} \\
\hline & \multicolumn{2}{|c|}{ Total de imóveis } & \multicolumn{2}{|c|}{ Área total } & \multicolumn{2}{|c|}{ Total de imóveis } & \multicolumn{2}{|c|}{ Área Total } \\
\hline & número & $(\%)$ & (mil ha) & (\%) & número & $(\%)$ & (mil ha) & (\%) \\
\hline $\begin{array}{l}\text { Minifúndio } \\
\text { Pequena }\end{array}$ & 1.772 .870 & 60,6 & 24.036 & 7,8 & 2.214 .983 & 61,7 & 30.967 & 7,5 \\
\hline $\begin{array}{l}\text { Propriedade } \\
\text { Média }\end{array}$ & 821.003 & 28,1 & 49.570 & 16,0 & 968.072 & 27,0 & 61.158 & 14,7 \\
\hline $\begin{array}{l}\text { Propriedade } \\
\text { Grande }\end{array}$ & 235.904 & 8,1 & 62.340 & 20,1 & 286.111 & 8,0 & 79.808 & 19,2 \\
\hline Propriedade & 82.316 & 2,8 & 171.512 & 55,3 & 104.744 & 2,9 & 238.337 & 57,4 \\
\hline Outras & 12.111 & 0,4 & 2.570 & 0,8 & 14.057 & 0,4 & 5.299 & 1,3 \\
\hline Brasil & 2.924.204 & 100 & 310.030 & 100 & 3.587 .967 & 100 & 415.570 & 100 \\
\hline
\end{tabular}

Obs.:

Minifúndio - o imóvel rural com área inferior a um módulo fiscal.

Pequena Propriedade - imóvel rural de área compreendida entre 1 e 4 módulos fiscais;

Média Propriedade - o imóvel rural superior a 4 e até 15 módulos fiscais;

Grande Propriedade - o imóvel rural de área superior a 15 módulos fiscais.

Modulo Fiscal - Unidade de medida expressa em hectares, fixada para cada município, considerando os seguintes fatores: a) tipo de exploração predominante no municípios; b) renda obtida com a exploração predominante $c$ ) outras explorações existentes nos municípios que, embora não predominantes, sejam significativas em função da renda e da área utilizada; d) o conceito de propriedade familiar.

Fonte: Instituto Nacional de Colonização e Reforma Agrária - INCRA 
A inadequação da política agrícola praticada pelos últimos governos federais e seus efeitos na estrutura agrária são ressaltados em estudo de Gerson Teixeira (3), a partir dos resultados dos Censos Agropecuários realizados pelo Instituto Brasileiro de Geografia e Estatística (IBGE) de 1985 e de 1995/96. Pela primeira vez, desde do censo de 1950, ocorreu a redução do número de estabelecimentos agrícolas. Entre 1985 e 1995/96 observase a redução de 941.944 dessas unidades econômicas. Desse número, 70,3\% do total apresentavam áreas inferiores a 10 ha. Em outras palavras, os dados do IBGE indicam que a política agrícola não beneficiou os pequenos proprietários ou a economia familiar, tendo contribuído para a expulsão do trabalhador do campo.

A pequena propriedade emprega proporcionalmente mais na atividade agrícola do que a grande propriedade. Os estabelecimentos com área inferior a 1 ha, geram mais empregos que o conjunto das propriedade de tamanho superior a 500 ha.

O contingente ocupado na agricultura em 1985, segundo o IBGE, era de 23.394.881 pessoas. O novo censo registrou, por sua vez, uma redução de 23\% (5.463.991) dos trabalhadores ocupados nessa atividade, pois em 1995/96 esse universo totalizava 17.930.890 pessoas empregadas no campo brasileiro. A crise no campo evidencia-se também pela elevada participação do trabalho de menores de 14 anos na agricultura brasileira, em torno de 2.4 milhões de crianças e adolescentes, ou seja, 13,6\% do pessoal ocupado nessa atividade.

\section{Políticas para enfrentar o problema da desigualdade}

Ao ser homenageado por seus 80 anos, na Universidade de São Paulo em junho de 2000, em suas Reflexões sobre a crise brasileira, o mais importante economista brasileiro vivo, Celso Furtado, conclamou-nos a interrogar sobre as raízes dos problemas de nosso povo, assinalando: "acumulamos uma dívida externa descomunal, enfrentamos um endividamento interno do setor público que acarreta a desordem das finanças do Estado, enquanto metade da população sofre de carência alimentar. (...) Se prosseguirmos no caminho que estamos trilhando desde 1994, buscando a saída fácil do crescente endividamento externo e o do setor público interno, o Passivo Brasil inchará em um decênio de forma a absorver a totalidade da riqueza que acumulamos desde a proclamação da Independência".

Mais adiante, Furtado observa que "se admitimos que nosso objetivo estratégico é conciliar uma taxa de crescimento elevada com absorção do 
desemprego e desconcentração da renda temos de reconhecer que a orientação dos investimentos não pode subordinar-se à racionalidade das empresas transnacionais. Devemos partir do conceito de rentabilidade social a fim de que sejam levados em conta os valores substantivos que exprimem os interesses da coletividade em seu conjunto".

Para escapar à disjuntiva de desagregar-se ou deslizar para regimes autoritários de tipo fascista como resposta às tensões sociais crescentes, Furtado conclama-nos a "voltar à idéia de projeto nacional, recuperando para o mercado interno o centro dinâmico da economia. A maior dificuldade está em reverter o processo de concentração da renda, o que somente será feito mediante uma grande mobilização social. (...) O Brasil só sobreviverá como nação se se transformar numa sociedade mais justa e preservar sua independência política.”

Quais os instrumentos de política econômica que poderão nos levar a reverter esse quadro de maneira a construirmos uma nação civilizada e justa? São justamente aqueles que levam em consideração os grandes valores que movem a humanidade, que não são apenas a busca do interesse próprio, mas a busca da ética, da solidariedade, da justiça, da liberdade e da democracia. Podemos encontrar essa preocupação, por exemplo, em autores como Paul \& Greg Davidson (4), Philippe Van Parijs (5) e Amartya Sem (6).

Entre os instrumentos compatíveis com esses valores e objetivos estão:

- A prática do Orçamento Participativo, que tem possibilitado às pessoas de todos os segmentos da sociedade estarem participando mais intensamente das decisões acerca da aplicação dos recursos públicos, cujo exemplo maior, hoje de repercussão internacional, é o de Porto Alegre. Que foi implementado e aperfeiçoado em três gestões do PT, de Olívio Dutra, Tarso Genro e Raul Pont, e presentemente, adotado por Olívio Dutra no governo do Rio Grande do Sul.

- A realização de forma mais rápida e decidida da Reforma Agrária, com a adoção de medidas que possibilitem a desapropriação das áreas improdutivas, promovam o assentamento de maior número de famílias que estejam dispostas a cultivar a terra, com o devido apoio de assistência técnica agrícola e creditícia.

- O apoio às formas cooperativas de produção nas áreas rurais e urbanas, nos mais diversos setores de atividades, assim como a promoção da democratização das relações de produção entre empresários e trabalhadores em todas as empresas privadas e públicas.

- A expansão do microcrédito mediante instituições como as de Bancos do Povo. Por exemplo, a criação da instituição PortoSol, iniciada em 
Porto Alegre, em 1996, com apoio dos governos municipais e estaduais, que acabou servindo de padrão para o crescimento de uma diversidade de experiências que hoje têm sido implementadas por muitos governos municipais e estaduais, dos mais diversos partidos, inclusive pelo governo paulista. Para estimular a difusão dessas operações de crédito na economia brasileira, o BNDES criou programas que permitem a viabilização da expansão do microcrédito, de tal maneira a prover pequenas somas a pessoas e/ou grupos de pessoas solidárias, a taxas de juros relativamente modestas, para adquirirem instrumentos de trabalho que lhes possibilitem realizar atividades produtivas, viabilizando a sua sustentação com dignidade (7).

- A universalização e melhoria das oportunidades de educação.

- A expansão e melhoria significativa dos serviços de saúde.

- Os programas que visem à capacitação das pessoas que estejam em dificuldade de encontrar trabalho, sejam os jovens que procuram o seu primeiro emprego e gostariam de realizar um estágio com modesta remuneração, ou os de mais idade, que pelo treinamento em novas funções ainda muito podem contribuir com a sua experiência, a exemplo dos programas Primeiro Emprego, Bolsa Trabalho ou Começar de Novo.

- A implantação de um Programa de Garantia de Renda Mínima (PGRM), que deve se expandir gradualmente, começando como um programa relacionado à educação, mas caminhando, posteriormente, em direção ao objetivo de se garantir a todas as pessoas residentes no Brasil o direito inalienável de participar da riqueza da nação, de receber uma renda suficiente para atender às suas necessidades fundamentais como um direito à cidadania. Assim, chegaremos em breve à possibilidade de todas as pessoas, não importa a origem, a raça, o sexo, a idade, a condição civil ou sócio-econômica, receberem uma renda básica incondicional, suficiente para atender às suas necessidades vitais. Será um direito ex-ante, sem qualquer exigência que não seja a moradia da pessoa no país. Todos contribuirão para o financiamento desse programa, sendo que a maior contribuição deve ser a dos que têm mais. Para os que não têm ainda familiaridade com essa proposição, observo que em 1986 fundou-se a Rede Européia da Renda Básica, a Basic Income European Network (BIEN), que vem se constituindo num fórum para analisar e difundir as experiências de renda mínima, bolsa-escola, imposto de renda negativo, crédito fiscal, renda de cidadania. Em países dos cinco continentes há instituições congêneres, inclusive a Basic Income Earth Network, também BIEN, reconhecida pela primeira, que está sediada na minha home-page:

http://www.senado.gov.br/web/senador/eduardosuplicy.htm. Em 
5 e 6 de outubro de 2000, em Berlim, realizou-se o VIII Congresso Internacional da BIEN. Os que desejarem informações podem acessar o site http://www.etes.ucl.ac.be/BIEN/bien.htm

A implantação da garantia de uma renda mínima, a transferência de recursos em dinheiro para pessoas ou famílias que não alcancem determinado patamar de renda, é um dos instrumentos fundamentais para atingir simultaneamente os seguintes objetivos:

- Garantir a erradicação da miséria.

- Incentivar a freqüência e permanência das crianças e adolescentes nas escolas.

- Combater o trabalho infantil, abrindo mais oportunidades de trabalho aos adultos.

- Resgatar o direito da criança de brincar e estudar.

- Acabar com a desnutrição infantil e dos adultos.

- Tirar a criança e o adolescente das ruas.

- Qualificar os membros adultos das famílias para o mercado de trabalho.

- Possibilitar às famílias pobres o resgate de sua dignidade.

- Aumentar significativamente o ritmo de crescimento da economia, sobretudo em função da maior demanda por bens de primeira necessidade, incluindo os alimentos, mas também porque se ampliarão as possibilidades de trabalhadores serem empregados.

- Melhorar a segurança pública, com a diminuição da criminalidade, em função da melhoria das condições sociais.

Como fazer para que mais rapidamente no Brasil possam os governos da União, dos estados e dos municípios instituir a garantia de uma renda mínima? Apresentei no Senado, em abril de 1991, o projeto de lei que institui o PGRM segundo o qual toda a pessoa de 25 anos ou mais que não recebesse o equivalente hoje a cerca de $\mathrm{R} \$ 350,00$ teria o direito de receber $30 \%$, ou até $50 \%$, da diferença entre aquela quantia e a renda da pessoa. Nesse mesmo ano, desenvolveram-se debates no âmbito do PT que levaram o economista José Márcio Camargo a propor o relacionamento da garantia de uma renda às famílias carentes, que tivessem crianças de até 14 anos de idade freqüentando escola, proposição que também foi abraçada por Cristovam Buarque. O PGRM foi aprovado em dezembro de 1991 no Senado, enviado à Câmara dos Deputados, onde recebeu parecer favorável do deputado Germano Rigotto (PMDB-RS), mas até hoje, apesar de pronto, aguarda para ser votado na Comissão de Finanças daquela Casa. 
Já são muitos os municípios que implementaram programas de renda mínima associados à educação ou bolsa-escola, a partir dos exemplos pioneiros e simultâneos do prefeito José Roberto Magalhães Teixeira (PSDB), de Campinas, com o PGRM, e do governador Cristovam Buarque (PT), do Distrito Federal, com o Bolsa-Escola, ambos em 1995. Também, já ao final de 1995, do prefeito Antônio Palocci, que introduziu o Programa de Garantia de Renda Mínima em Ribeirão Preto.

Os resultados daquelas e de outras experiências positivas de renda mínima e bolsa-escola se alastraram por muitos municípios e alguns estados, vindo a ter repercussão no Congresso Nacional, onde surgiram mais seis projetos de lei dos deputados Nelson Marquezan (PSDB-RS), Chico Vigilante (PT-DF) e Pedro Wilson (PT-GO) e dos senadores Ney Suassuna (PMDB -PB), Renan Calheiros (PMDB-AL) e José Roberto Arruda (PSDB-DF). Dessas experiências e projetos resul-

programas de renda mínima associados à educação ou bolsa-escola ...

tou a Lei 9.533/97 que autoriza a União a financiar em $50 \%$ os gastos dos municípios que adotarem programas de renda mínima associados à educação. Trata-se de uma lei muito restrita, uma vez que para os anos 1998 a 2002 contempla apenas aquelas administração municipais que tenham renda e arrecadação per capita inferiores à média do respectivo Estado, podendo os demais serem contemplados a partir de 2003. Além disso, o benefício a cada família cuja renda per capita for inferior a meio-salário mínimo é de apenas R\$ 15,00 x número de crianças até 14 anos, menos metade da renda familiar per capita.

Segundo levantamento do Ministério da Educação, até junho 2000, 1.481 municípios assinaram convênios para implementar o PGRM nos moldes da lei 9.533/97. Esses programas beneficiarão 946.981 famílias e abrangerão 1.861 .060 crianças, correspondendo a um gasto anual de R\$ 439.506.490,00, dos quais $50 \%$ de responsabilidade da União e os $50 \%$ restantes dos municípios. No estado de São Paulo já assinaram convênios com o MEC 179 municípios beneficiando 30.506 famílias, atingindo 57.658 crianças, com gasto estimado em R\$ 11.787.930,00.

Vamos supor que estados ou municípios queiram implementar programas de renda mínima com formato mais generoso do que o previsto na lei 9.533/97. Como é que governos como o do estado do Rio Grande do Sul ou do Piauí, ou do município de São Paulo, todos com 13\% de sua receita líquida comprometida com o pagamento da dívida para com a União, 
terão condições de enfrentar uma despesa que pode significar algo em torno de 2 a 3\% de seus orçamentos, já que há tantos outros compromissos, como nas áreas da educação, da saúde e da habitação a enfrentar?

No caso do município de São Paulo, desde 1996 foi aprovada uma lei do vereador Arselino Tatto (PT), que dá o direito a todas as famílias com renda inferior a três salários mínimos mensais e que tenham crianças até 14 anos freqüentado escolas ou creches públicas, a receber $33 \%$, ou até $66 \%$, da diferença entre aquele patamar, hoje $\mathrm{R} \$ 453,00$, e a renda da família. Depois de vetada pelo prefeito Paulo Maluf, com o veto derrubado pela Câmara Municipal, a lei foi considerada promulgada pelo Tribunal de Justiça, em julho de 1999, mas até hoje aguarda a regulamentação.

A Fundação SEADE realizou uma estimativa segundo a qual residem no município de São Paulo 9.923 mil habitantes ou 3,063 milhões de famílias, das quais, 309 mil, correspondendo a 10,1\% do total, possuem renda de até três salários mínimos mensais e crianças com até 14 anos na escola. Considerando-se a renda familiar total média de 1,68 salário mínimo e a renda familiar per capita média de 0,46 salário mínimo, essas famílias teriam o direito, segundo a lei do vereador Arselino Tatto, a um complemento mensal médio da ordem de 0,44 salário mínimo, hoje equivalente a R\$ 66,44 , o que corresponderia a um desembolso mensal estimado em R\$ 20.512.834,00 ou R $\$ 246,1$ milhões por ano. Levando-se em conta a experiência internacional, de que programas bem-sucedidos atingem cerca de $70 \%$ do universo das pessoas carentes, ainda assim chegaríamos por ocasião de sua plena implantação a uma quantia da ordem de R\$ 172 milhões, ou 2,2\% do Orçamento Municipal para 2000, que é da ordem de R\$ 7,5 bilhões.

Caso o município não possa dispor desse montante, um primeiro passo pode ser regulamentar o PGRM de modo a beneficiar inicialmente todas as famílias que recebam até meio salário mínimo per capita e tenham crianças de até 14 anos estudando. A Fundação SEADE estima que elas totalizam 165 mil, correspondendo a $5,4 \%$ do total de famílias do município de São Paulo e a 733 mil pessoas. A sua renda familiar total média é de 1,04 salário mínimo, a renda familiar per capita média de 0,23 salário mínimo e a complementação mensal média seria de 0,65 salário mínimo, ou R\$ 97,15. Assim o gasto mensal estimado do PGRM ficaria em R\$ 16,3 milhões e, o anual, em R\$ 195 milhões. Se forem atendidas $70 \%$ das famílias potenciais beneficiárias, a soma chegaria a R\$ 136,9 milhões, ou 1,8\% do Orçamento Municipal de 2000.

Essa quantia pode parecer demasiada se ficar apenas a cargo da prefeitura. Entretanto, se forem considerados os três níveis de governo, a viabilidade do programa se torna muito maior. É relevante notar, como demons- 
trado na tabela 10 , que com um custo adicional de $\mathrm{R} \$ 35$ milhões pode-se atingir mais 144 mil famílias. A razão de o custo ser maior para as famílias que ganham até 0,5 salário mínimo resulta do fato de, para elas, o benefício ser também maior.

Tabela 10

Simulação da abrangência e custo do PGRM do município de São Paulo

\begin{tabular}{l|l|c|c}
\hline \multicolumn{1}{c|}{ Programa } & \multicolumn{1}{|c|}{ População beneficiária } & $\begin{array}{c}\text { População } \\
\text { atendida } \\
\text { (em famílias) }\end{array}$ & $\begin{array}{c}\text { Custo } \\
\text { (R\$ } \\
\text { milhões) }\end{array}$ \\
\hline $\begin{array}{l}\text { Suplementação de 33\% } \\
\text { da diferença entre três }\end{array}$ & $\begin{array}{l}\text { Famílias com renda total } \\
\text { de até três Salários Mínimos } \\
\text { e crianças de até 14 anos } \\
\text { freqüiontando a escola ou } \\
\text { renda familiar }\end{array}$ & 309 mil & 172 \\
\hline $\begin{array}{l}\text { Suplemes públicas } \\
\text { da diferençação entre três } 33 \%\end{array}$ & $\begin{array}{l}\text { Famílias com renda total } \\
\text { de até 0,5 Salário Mínimo e } \\
\text { crianças de até 14 anos } \\
\text { freqúientando a escola ou } \\
\text { renínimos e }\end{array}$ & 165 mil & 137 \\
\hline renda familiar
\end{tabular}

Considerando o já exposto no início deste texto, que levou ao agravamento das condições sociais da população, incluindo aquela das regiões metropolitanas, é mais do que lógico que a União venha a se responsabilizar por uma parte do programa. Dessa forma, será legítimo que a prefeitura solicite ao presidente Fernando Henrique Cardoso que a União concorde em repassar parte dos $13 \%$ da receita liquida do município que lhe é devida, para ser aplicado no PGRM.

Por seu turno, também o governo estadual de São Paulo instituiu recentemente, ainda que não em lei, dois programas relacionados com a garantia de uma renda familiar: o Complementando a Renda para famílias que recebam até $R \$ 50,00$ mensais e que passam a ter direito a $R \$ 50,00$ multiplicados pelo número de membros da família, desde que as crianças freqüentem a escola; e o programa Alimenta São Paulo, que distribui cestas básicas para as famílias que ganhem até meio salário mínimo mensal per capita, com requisitos semelhantes. Acredito ser razoável que a prefeitura articule com o governador Mário Covas a forma mais adequada de complementar a renda das famílias do município. 
Seria próprio que os governos estaduais, em coordenação com os governos municipais, despendessem esforços no sentido de implementar o PGRM com um desenho que contribua para, simultaneamente, erradicar a pobreza absoluta e o trabalho infantil, elevar o nível de emprego e a atividade econômica, e melhorar a distribuição da renda.

Ressalta-se que quando um programa é implementado de forma segmentada, apenas por alguns municípios, acaba provocando uma espécie de "fechamento de fronteiras". Para evitar a vinda de migrantes, esses municípios introduzem restrições para o acesso ao programa, entre elas o de tempo mínimo de residência, as quais só serão superadas com a extensão do programa para todo o território nacional. Idealmente para todo o continente, do Alasca até a Patagônia.

Nós, brasileiros, precisamos estar conscientes de que os países desenvolvidos utilizam instrumentos de complementação da renda dos trabalhadores e que, graças a esses mecanismos passam a receber mais. Ressalto que a existência desses programas, como o Earned Income Tax Credit (EITC), ou Crédito Fiscal por Remuneração Recebida, atualmente beneficiando mais de 20 milhões de famílias nos EUA, torna mais competitiva aquela economia em relação à nossa e tem contribuído para que a taxa de desemprego naquele país esteja próxima de $4 \%$, a mais baixa dos últimos 30 anos. Mediante a coordenação de instrumentos como salário mínimo, renda mínima e semelhantes, os EUA, o Canadá, o Reino Unido, entre outros países europeus, atingem o objetivo de melhorar as condições de emprego e renda.

Um desenho racional do PGRM deve procurar evitar as armadilhas de desemprego e pobreza, porque deve sempre levar em consideração a manutenção do estímulo ao progresso e ao trabalho. Daí porque tenho defendido o desenho na forma de um imposto de renda negativo, seja para a pessoa adulta, como no projeto de lei que institui o PGRM que apresentei em 1991, aprovado pelo Senado, e que tramita na Câmara Federal, ou para a família, tal como também apresentado por mim no Senado, faltando apenas ser aprovado na Câmara. Essa proposição modifica a fórmula do benefício previsto na Lei 9.533/97 já mencionada, pelo qual uma família com renda inferior a meio salário mínimo mensal per capita, com crianças até 14 anos freqüientando a escola, passaria a ter o direito de receber $40 \%$ (proporção que poderia ser alterada pelo Executivo) da diferença entre o número de pessoas na família vezes meio salário mínimo e a sua renda.

A outra forma de sempre haver o estímulo ao trabalho, além disso, minimizar quaisquer burocracias de controle sobre o que cada pessoa ganha e, sobretudo, evitar qualquer estigma ou vergonha de a pessoa declarar 
a sua situação, é a introdução da renda básica como um direito incondicional. Há uma experiência no mundo, que já dura 20 anos, a qual vem dando resultados muito positivos nesta direção.

Trata-se do sistema de dividendos proporcionado pelo Fundo Permanente do Alasca (FPA). Em 1976 o governador Jay Hammond propôs à Assembléia Legislativa e ao povo do Alasca que separassem $50 \%$ dos royalties da exploração de recursos naturais, como o petróleo, para um fundo que pertenceria a todos os residentes no estado. Foi aprovado, inclusive por referendo, na proporção de $2 \times 1$. Por quatro anos discutiu-se como aplicar os recursos. Alguns propunham que fosse aberto um banco de desenvolvimento, como o nosso BNDES. Outros se opuseram, ponderando que seria uma maneira de destinar recursos subsidiados para empresários que, embora gerando investimentos e empregos, acarretaria uma intensa concentração de riqueza. Por isso optaram por uma sistemática que beneficiasse igualmente a todos. Decidiu-se que os recursos do FPA seriam aplicados em títulos de renda fixa, ações de empresas do Alasca, dos EUA, do exterior, inclusive do Brasil, e em empreendimentos mobiliários. $\mathrm{O}$ valor patrimonial do Fundo passou de US\$ 1 bilhão em 1980, para US\$ 28,1 bilhões em 2000. Em 1976 o Alasca tinha cerca de 300 mil habitantes. Hoje pouco mais de 600 mil. Cada residente no estado cadastra-se em um banco de dados. Quem assim procede recebe, a cada ano, em outubro, um dividendo que cresceu de US\$ 300,00 em 1980, para US\$ 1.679,84 em 1999. Em 2000, uma família de seis pessoas receberá cerca de US\$ 12 mil como um direito de participar da riqueza do estado do Alasca. Algo muito semelhante ao que, em 1795, foi proposto em Justiça Agrária por Thomas Paine, um dos maiores ideólogos das Revoluções Americana e Francesa, num ensaio escrito para o Diretório e a Assembléia Nacional da França.

Em estudos realizados, economistas observaram que o sistema de dividendos do Fundo Permanente do Alasca tem contribuído para a maior estabilidade da economia daquele estado. Poderiam alguns argumentar que o Alasca tem uma renda per capita cerca de seis vezes maior que a do Brasil e uma população muito menor. Mas se quiséssemos proporcionar algo semelhante e equivalente aos 167 milhões de brasileiros isso significaria cerca de R \$ 40,00 mensais para cada um. Esse valor faria uma grande diferença numa família de seis pessoas que passaria a ter R 240,00 mensais no seu orçamento, ou RS 480,00 por pessoa por ano, o que representaria o montante de R\$ 80,1 bilhões ao ano para atender a todos brasileiros. Considerando que o Orçamento da União de 2000 fixou o valor de R 78 , 1 bilhões para o pagamento dos juros da dívida pública (interna e externa), a introdução paulatina de programas de garantia de renda mínima, com a meta de 
chegarmos um dia a uma renda básica incondicional, estaria dentro das nossas possibilidades orçamentárias. Será a maneira de não discriminar os pobres - pobres sem filhos em certa faixa etária, adultos pobres sem filhos, idosos pobres ou quem quer que seja. Assim, os formatos atuais dos programas de renda mínima e bolsa-escola no Brasil deverão, no futuro, ser superados para garantir a todas as pessoas o direito a uma renda de cidadania. Este passo certamente contribuirá para tornar o Brasil mais justo.

A instituição de um programa de garantia de renda mínima em nível nacional é consistente com a recomendação de um grande brasileiro que nos deixou recentemente. Em seu último artigo para o Jornal do Brasil, Barbosa Lima Sobrinho escreveu que "a igualdade é pressuposto básico da democracia, sem ela não se tem condição de sobreviver”. As políticas públicas propostas nesse trabalho, se adotadas com todo o vigor, serão capazes de assegurar a todos os brasileiros o direito à vida com dignidade, resultando, portanto, em maior igualdade e fortalecimento da democracia.

\section{Notas}

1 Ricardo Paes de Barros, Ricardo Henriques e Rosane Mendonça, Desigualdade e pobreza no Brasil: a estabilidade inaceitável. Rio de Janeiro, IPEA, 2000.

2 Márcio Pochmann, A quarta fase da desigualdade distributiva no Brasil, artigo publicado em Valor Econômico, 24 jul. 2000.

3 Gerson Teixeira, O Censo Agropecuário de 1996: uma radiografia dos resultados de 11 anos de neoliberalismo no campo brasileiro. In: Geraldo Cândido, $A$ situação e perspectivas da agricultura brasileira. Brasília, Senado Federal, 2000.

4 Paul \& Greg Davidson, Economics for civilized society. New York / London, W.W. Norton \& Company, 1988.

5 Philippe Van Parijs, O que é uma sociedade Justa? São Paulo, Ática, 1997.

6 Amartya Sen, Desenvolvimento com liberdade. São Paulo, Companhia das Letras, 2000.

7 Os programas do BNDES destinados ao fortalecimento do microcrédito no Brasil podem ser observados em Lara Goldnark et al.., A situação das microfinanças no Brasil. Rio de Janeiro, BNDES, 2000.

Eduardo Matarazzo Suplicy, senador (PT-SP), é professor de Economia na Escola de Administração de Empresas de São Paulo da Fundação Getúlio Vargas, Ph.D. em Economia pela Michigan State University (EUA), onde defendeu tese sobre "Os efeitos das minidesvalorizações na economia brasileira (1973). 